\title{
Study on specific proteins involved in articular cartilage regeneration activity induced by decalcified bone transplantation
}

\author{
Min Wang, Tianming Dai, Zhencheng Feng, Qingqi Meng, Wen Wang, Siming Li \\ Department of Orthopaedics, Guangzhou Red Cross Hospital, Jinan University, Guangzhou, China \\ Contributions: (I) Conception and design: M Wang, S Li, W Wang; (II) Administrative support: M Wang, S Li, W Wang; (III) Provision of study \\ materials or patients: M Wang, S Li, W Wang; (IV) Collection and assembly of data: T Dai, Z Feng; (V) Data analysis and interpretation: Q Meng, \\ T Dai, Z Feng; (VI) Manuscript writing: All authors; (VII) Final approval of manuscript: All authors. \\ Correspondence to: Wen Wang, Siming Li. Department of Orthopaedics, Guangzhou Red Cross Hospital, Jinan University, Guangzhou 510220, \\ China. Email: wangwarren88@hotmail.com; drsmli@hotmail.com.
}

Background: Through a comprehensive analysis of the joint synovial fluid produced in the process of rabbit articular cartilage regeneration, the role and characteristics of knee synovial fluid in the process of decalcified bone transplantation-induced articular cartilage regeneration were explored.

Methods: Twenty New Zealand white rabbits (approximately $2.5 \mathrm{~kg}$ in weight) were selected, and bilateral distal femoral bones from two randomly selected rabbits were extracted. After decalcification, the bones were cut into $2 \mathrm{~mm} \times 4 \mathrm{~cm}$ long decalcified bone strips. Meanwhile, the other 18 rabbits were randomly divided into three groups: the test group ( 8 rabbits), the positive control group (6 rabbits), and the blank group (4 rabbits). In the test group, the decalcified bone joint was transplanted into the rabbits at the articular cartilage defect; in the positive control group, the articular cartilage defect of the rabbits were treated and put aside; in the blank group, no rabbits were treated. On the day of transplantation, and on the 4th, 8th, 12th, and 16th weeks after transplantation, the joint synovial fluid of each group was taken for two-dimensional polyacrylamide gel electrophoresis (2D-PAGE), matrix-assisted laser desorption/ionization-time-of-flight mass spectrometry (MALDI-TOF-MS) analysis, and related database verification and identification, and compared with the positive control group and the blank group.

Results: Using 2D-PAGE to separate various proteins in the synovial fluid of the rabbit knee joints, it was found that there were differential protein spots in the test group compared with the blank group and the positive control group. After conducting a comparative search and query in the UniProt database, through comprehensive analysis, it was finally found that three proteins with molecular weights of 23,429.4, 57,431.4, and 26,071.1 that may be related to the regeneration of articular cartilage appeared in the test group.

Conclusions: In the process of inducing the regeneration of articular cartilage using decalcified bone transplantation, knee joint synovial fluid produced specific proteins, which may play an important role in the regeneration of articular cartilage. These findings may offer novel ideas in laying a foundation for the indepth study of articular cartilage regeneration.

Keywords: Decalcified bone; articular cartilage regeneration; specific protein; two-dimensional gel electrophoresis; mass spectrometry analysis

Submitted Dec 04, 2020. Accepted for publication Jan 21, 2021.

doi: $10.21037 /$ atm-20-8195

View this article at: http://dx.doi.org/10.21037/atm-20-8195 


\section{Introduction}

The structure of the articular cartilage, which covers the surface of joints and is composed of chondrocytes and matrix, is critical for the function of daily activities. It is responsible for buffering stress, preventing abrasion, absorbing shock, and lubricating joint surfaces (1). When the articular cartilage wears and degenerates, the joints become fragile and vulnerable, and lose flexibility, which in serious cases can affect normal motor function. The current clinical treatment of articular cartilage is mainly conservative treatment, including oral nutrition cartilage drugs, continuous passive movement of joints, etc. (2); and surgical repair, including chondrocyte transplantation, washing the joint cavity (3), induced regeneration, etc. Generally these methods can temporarily relieve symptoms and relieve pain, but they cannot fundamentally restore the normal structure and function of cartilage (4).

In recent years, autologous chondrocyte transplantation has shown broad prospects for the repair of cartilage defects. However, this approach requires precise and safe laboratory work along with delicate surgery, and thus its clinical application requires further investigation (5). Articular cartilage is a thin viscous elastic layer that covers the surface of sports joints (6). Its regenerative capacity is limited. After cartilage defects, it is very difficult to repair. Additionally, articular chondrocytes are highly differentiated terminal cells, and their ability to divide into mature articular cartilage is extremely weak (7). Because the articular cartilage has low friction and high compression resistance, it helps the smooth movement of joints. The articular cartilage dysfunction can greatly interfere with the movement of the limbs and trunk, and cause pain (8). Therefore, many research teams are committed to studying how to induce articular cartilage regeneration in cartilage defects. In the 1980s, a research team carried out research on the use of decalcified allogeneic cartilage to repair joint damage, which laid the foundation for studying the mechanism of articular cartilage regeneration induced by decalcified allogeneic bone joint (9).

Allogeneic decalcified bone is one of the commonly used materials to induce articular cartilage injury and regeneration, and has garnered considerable attention in the past decade. Baker et al.'s study (2) found that interferon gamma (IFN- $\gamma$ ) pretreatment of allogeneic bone marrow stromal cells (BMSCs) combined with decalcified bone matrix to repair rabbit radial defect could significantly promote bone formation and improve the repair effect to radial defects. Additionally, Feng and colleagues (10) found that allogeneic demineralized bone matrix and BMSC's co-cultured and implanted into the knee joint could form cartilage-like tissues, effectively repairing articular cartilage defects. Our research team (11) also confirmed that the use of implanted decalcified allogeneic bone or cartilage can induce articular cartilage regeneration, thereby repairing the staged osteoarticular defects in rabbits.

Joint synovial fluid is the only way for mature articular cartilage to obtain nutrients, and the examination of joint synovial fluid is the objective index that can best directly reflect the changes of the intra-articular environment in the process of articular cartilage injury and regeneration. Based on this viewpoint and previous research results, this study aimed to transplant self-made decalcified allograft bone into the knee joint defect site of New Zealand rabbits and perform intramedullary fixation with Kirschner wire. The joint synovial fluid and serum of the white rabbits were extracted for analysis by body fluid proteomics. The purpose of this was first to determine whether or not the joint synovial fluid and serum had the same protein after transplantation. The second purpose was to ascertain the differences between the joint defect of the non-transplanted group and the normal joint group, in order to identify specific proteins produced by the body in the process of articular cartilage regeneration after transplantation. Based on this, the relevant proteins in the process of articular cartilage regeneration could be clarified for further discussion.

We present the following article in accordance with the ARRIVE reporting checklist (available at http://dx.doi. org/10.21037/atm-20-8195).

\section{Methods}

\section{Preparation of the allogeneic decalcified bone graft and establishment of the rabbit knee articular cartilage defect model}

Experiments were performed in compliance with Chinese national guidelines for the care and use of animals. This study was approved by the Medical Ethics Committee of Guangzhou Red Cross Hospital, Jinan University (no. 2018-077-01). Twenty adult New Zealand white rabbits, each weighing approximately $2.5 \mathrm{~kg}$, were purchased from the Guangdong Animal Experiment Center. Two rabbits were randomly selected, from which the bilateral distal femur bones were extracted after the rabbits were killed by 
air embolization. The joint capsule, ligaments, periosteum, and soft tissue around the distal femur bone were removed, wrapped with low-melting paraffin, and immersed in $0.6 \mathrm{~mol} / \mathrm{L}$ hydrochloric acid solution for $24 \mathrm{~h}$ of decalcification. Next, the samples were washed with normal saline and then cut into $2 \mathrm{~mm} \times 4 \mathrm{~cm}$ long decalcified bone strips, put in a dry bottle at $4^{\circ} \mathrm{C}$, and stored for future use.

Another 18 rabbits were randomly divided into three groups: the test group ( 8 rabbits), the positive control group (6 rabbits), and the blank group (4 rabbits). The blank group was not treated, while the rabbits in the test group and the positive control group were anesthetized by intravenous injection into the ear margin and subjected to the following procedure: an incision was made at the medial margin of the right hind leg humeroradial joint, the flexion humeroradial joint was dislocated, and $20 \mathrm{~mm}$ of proximal radius was obtained by thread saw. The joint cavity was flushed with normal saline to remove tissue debris, blood clots, and other material before transplantation. The preprepared graft material was taken to fix the joint defect with Kirschner wire, with the test group being transplanted with allogeneic decalcified bone joint, the positive control group being transplanted with nothing, and the blank group not receiving any treatment. The combination degree of the graft material and the joint defect area was fused as much as possible. After the joint reduction was satisfactory, the tibial-femoral joint was sutured layer by layer.

The rabbits moved freely in the rabbit cage after operation, and were intramuscularly injected with 200,000 units of penicillin sodium once a day for 3 consecutive days. The dressing was changed regularly and the stitches were taken out after 10 days.

\section{Extraction of synovial fluid and total protein}

On the day after transplantation and at week 4, week 8 , week 12 , and week 16 after transplantation, $0.8-1 \mathrm{~mL}$ of rabbit joint fluid of each group was drawn into an Eppendorf (EP) tube separately and then centrifuged at $3,000 \mathrm{r} / \mathrm{min}$ for $30 \mathrm{~min}$ at $4{ }^{\circ} \mathrm{C}$; at last, the supernatant was aspirated. Five tubes were randomly selected from each group, and were frozen and thawed 3 times at $-70^{\circ} \mathrm{C}$. After mixing, 4 times the volume of prechilled acetone (containing $1 \mathrm{~mol} / \mathrm{L}$ phenylmethylsulfonyl fluoride) was added into the tubes which were then precipitated at $-20{ }^{\circ} \mathrm{C}$ for $2 \mathrm{~h}$, centrifuged at $20,000 \times \mathrm{g}$ for $10 \mathrm{~min}$ at $4^{\circ} \mathrm{C}$, washed with pre-cooled acetone, and drained. After lysis, a 2-h ice bath was used to dissolve the precipitate.
A ProteoPrep Blue Albumin Depletion Kit (SigmaAldrich, St. Louis, MO, USA) and a 2-D Clean-Up Kit (GE Healthcare, Chicago, IL, USA) were used to remove albumin, globulin, salt, and lipid from samples. The Bradford protein assay was used to measure the protein concentration, and the measurement was repeated 3 times to obtain the average value.

\section{Two-dimensional gel electrophoresis}

Two $10 \%$ acrylamide gels, each of $40 \mathrm{~mL}$, were prepared. The dry glue strips frozen at $-20{ }^{\circ} \mathrm{C}$ were removed and balanced at room temperature for $10 \mathrm{~min}$. Glue strip balance buffer I and the glue strip balance buffer II were prepared, and the glue strips were transferred to the swelling plate. Each glue strip tank was added with a glue strip and $5 \mathrm{ml}$ of glue strip balance buffer I, placed in a shaker to equilibrate for $15 \mathrm{~min}$, then mixed with rubber strip balance buffer II to equilibrate again for $15 \mathrm{~min}$. After the second equilibration, the balance solution was discarded, and the remaining balance solution was blotted dry.

The glue strips were taken out, the glue surface was immersed in $1 \times$ electrophoresis buffer, the acrylamide gel surface was placed in complete contact with the glue strip, and the low melting-point agarose was used to seal the glues. The gel was transferred into the electrophoresis tank, with the initial constant current of $5 \mathrm{~mA} / \mathrm{gel} / 17 \mathrm{~cm}$. After the sample had completely ran out of the immobilized $\mathrm{pH}$ gradient (IPG) glue strip, the constant current was changed to $20-30 \mathrm{~mA} / \mathrm{gel} / 17 \mathrm{~cm}$. The electrophoresis was stopped when the bromophenol blue indicator reached $0.5 \mathrm{~cm}$ from the bottom edge.

\section{Image analysis and matrix-assisted laser desorption/ ionization-time-of-flight mass spectrometry (MALDI- TOF-MS)}

After each glue strip was sensitize for 30 minutes, secondary pure water was used to rinse them 4 times for $30 \mathrm{~s}$. Next, silver staining was performed for $30 \mathrm{~min}$ in dark conditions, the two-dimensional glue was rinsed with secondary pure water 4 times for $30 \mathrm{~s}$, and the color was then developed for 2-10 minutes. At last, the reaction was terminated for 10 minutes. After rinsing the gel surface with secondary pure water, the two-dimensional electrophoresis gel exclusive image scanner was used for transmission scanning, and the gel was analyzed using PDQuest 8.0 2D software (Bio-Rad Laboratories, Hercules, CA, USA). In order to 
perform a comprehensive analysis and identification of proteins, the results were input into the local database, and the peptide sequence tags were queried by Mascot v.2.1 software (Matrix Science, London, UK) and then combined with the apparent isoelectric point of the corresponding point of bidirectional gel electrophoresis, the relative molecular mass, the number of matching peptides, and the sequence coverage.

\section{Results}

\section{Decalcified bone transplant surgery}

The situation after decalcified bone transplantation in rabbits is shown in Figure 1. One rabbit died after the operation; the decalcified bone grafts in the remaining rabbits grew well after the operation without inflammation.

\section{Two-dimensional gel electrophoresis image analysis}

After the level of high-abundance protein contained in the sample had reduced, image scanning software was used to perform intensity correction, spot detection, background extinction, homogenization, and matching on the separated protein spots. From the electrophoresis diagrams of each group, diagrams with similar distribution patterns and good matching were selected for analysis. Finally, it was found that there were differences in the joint fluid samples between the decalcified bone joint transplantation group (test) and those of the blank control group (blank). The differential points of each protein produced by electrophoresis were screened, and 17 differential points were selected among them for MALDI-TOF-MS. The results are displayed in Figure 2.

\section{Identification and analysis of differential protein spots}

MALDI-TOF-MS analysis and identification were performed on the 30 meaningful differential protein spots that appeared during the extraction of each group of protein electrophoresis maps, and the peptide sequence labels and sequence coverage indexes of all proteins within 10 points were obtained. After comprehensive analysis of the relative molecular weight and isoelectric point of mass-to-charge when combined with two-dimensional polyacrylamide gel electrophoresis (2D-PAGE), the corresponding results were input into the National Center for Biotechnology Information (NCBI) and UniProt protein database by
Mascot software for query and identification.

The identification query results are shown in Figure 3. The query results confirmed that there were three meaningful proteins in the knee joint fluid test group: (I) an unnamed protein with a molecular weight of 23,429.4; (II) a protein with a molecular weight of $57,431.4$, named catalase; (III) a protein with a molecular weight of 26,071.1, named EC-SOD (extracellular superoxide dismutase).

\section{Discussion}

Joint lesions caused by various reasons are very common in clinic. Due to the special structure of articular cartilage, with its lack of blood vessels, its self-renewal ability is limited, and repair of cartilage defects is very difficult (4). A good animal model is critical for studying the repair mechanism of articular cartilage defects. Based on our previous research $(9,11)$, in the current study, we induced a $20 \mathrm{~mm}$ bone joint defect in the proximal segment of the rabbits' radius and transplanted decalcified allogeneic bone joints with the same length as the defect in the radius defect area. X-ray photographs were used to confirm that the transplantation of decalcified allogeneic bone joint could induce the body to form new bone joints. The design of this animal model reduces the interference to the experimental results caused by the repair of the animal itself due to insufficient length of the defect; thus the transplant group's experimental results have more credibility. Allogeneic demineralized bone matrix is not new in the tissue engineering research of articular cartilage repair, as it has been used as a scaffold material for cartilage tissue engineering for quite some time (12). Demineralized bone matrix is also one of the most ideal bone graft materials at present. It can be used as a scaffold for the growth of new bone tissue and has the characteristics of bone conduction and bone induction to promote bone regeneration (13). Due to the large supply on the market, the use of demineralized bone matrix for bone treatment is relatively easy (14). Yanaga et al. (15) have confirmed that autologous chondrocytes can repair craniofacial or nasal deformities. Kim et al. (16) found that in the rabbit distraction osteogenesis model, injecting demineralized bone matrix into the distraction gap can stimulate the formation of regenerative bone. These studies and the results of this experiment all confirmed that decalcified allogeneic bone can be used as a graft material for clinical repair of segmental bone joint defects.

In order to confirm what factors play a key role in the process of repair after injury, we further collected the joint 
A

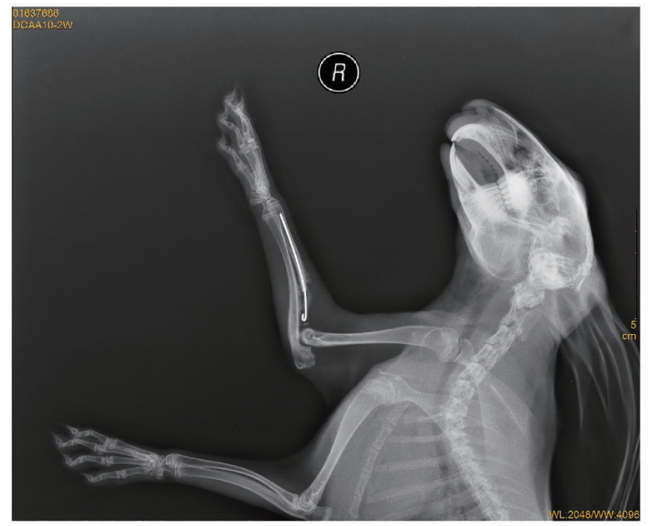

B

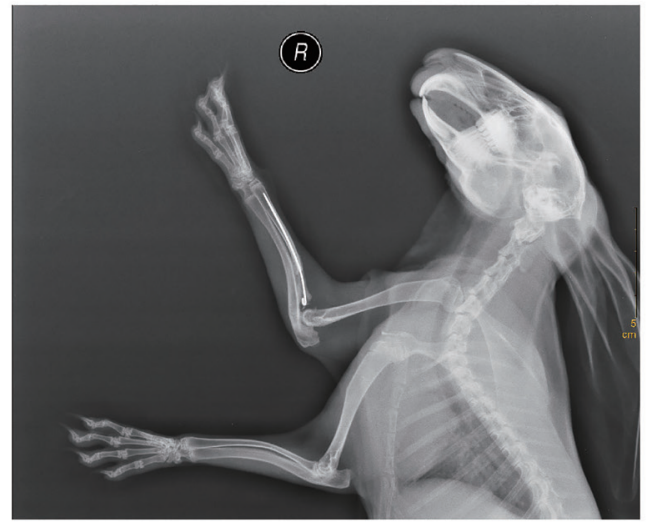

C

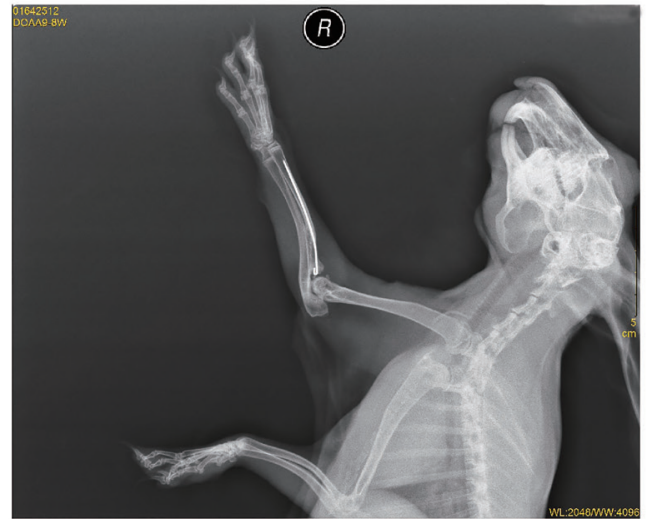

D

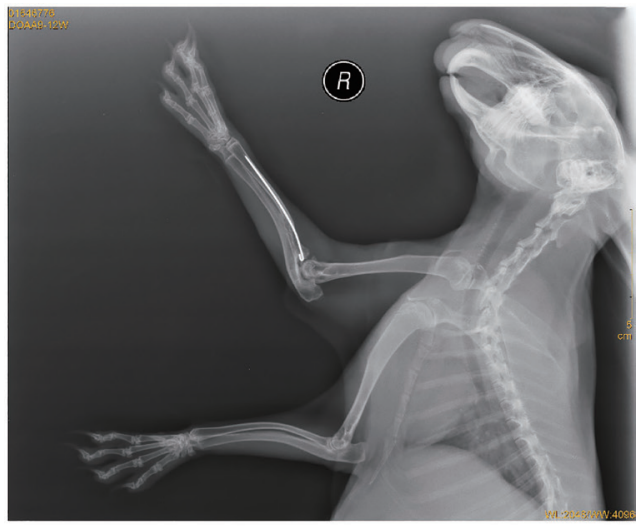

E

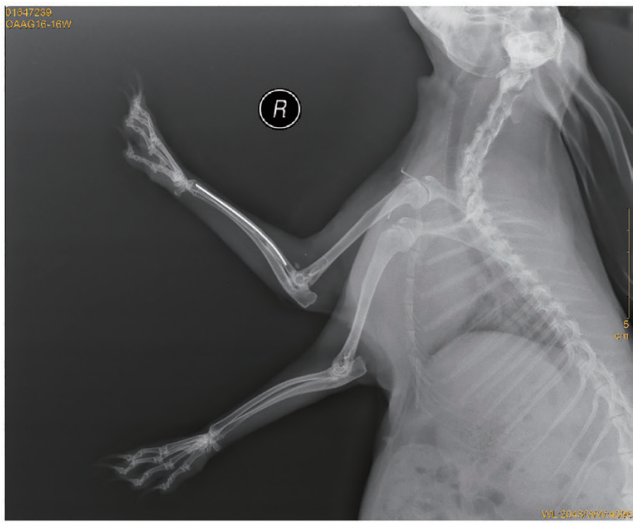

F

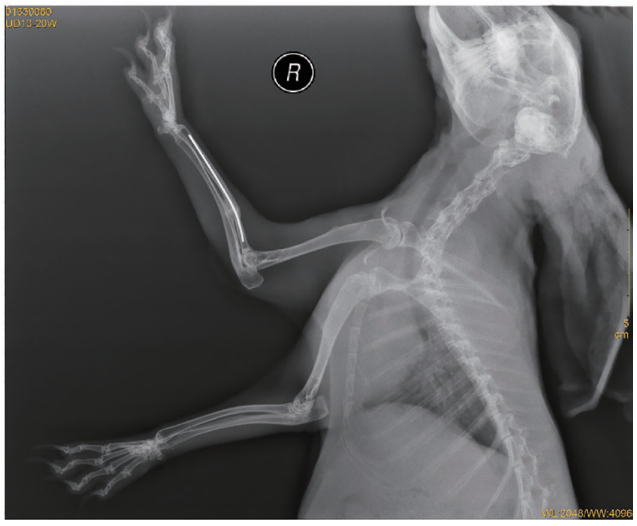

Figure $1 \mathrm{X}$-ray of decalcified bone transplantation surgery in rabbits. (A,B,C) X-rays of decalcified bone transplantation at 2, 4, and 8 weeks, respectively; (D,E,F) X-rays of decalcified bone transplantation at 12, 16, and 20 weeks respectively.

synovial fluid of each group of rabbits, and used MALDITOF-MS technology combined with 2D-PAGE separation technology to identify the presence of differential proteins in the joint synovial fluid of each group. Joint synovial fluid plays an important role in maintaining the motor function of joints, and changes in joint synovial fluid will occur during the occurrence and development of various osteoarthropathies (17). Zhang et al. (18) found that the increase of Indian hedgehog content in the synovial fluid of the human knee joint is related to early cartilage injury. Chockalingam et al. (19) also confirmed that tenascin-C in human synovial fluid can be used as a sign of joint damage, and it can stimulate further joint degradation. A large number of experimental studies have proven that some markers do exist in the process of articular cartilage repair, and these may play an important role in regulating cartilage 
Blank vs. Control

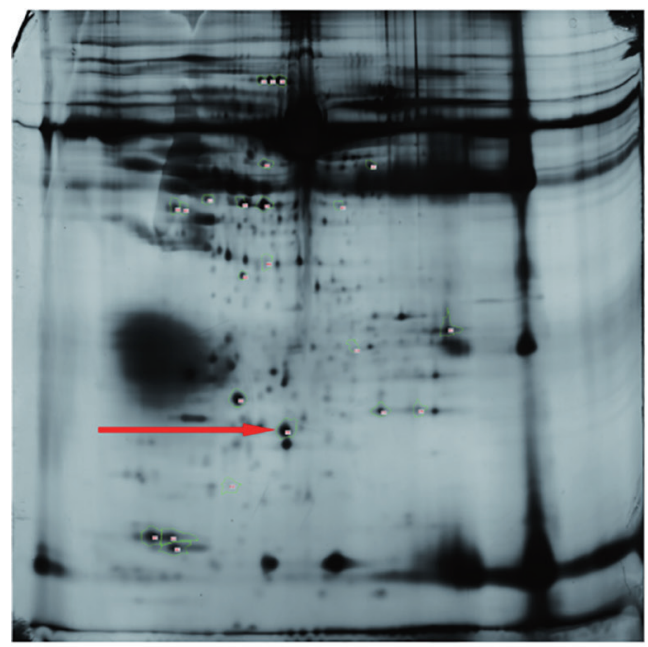

Test vs. Blank

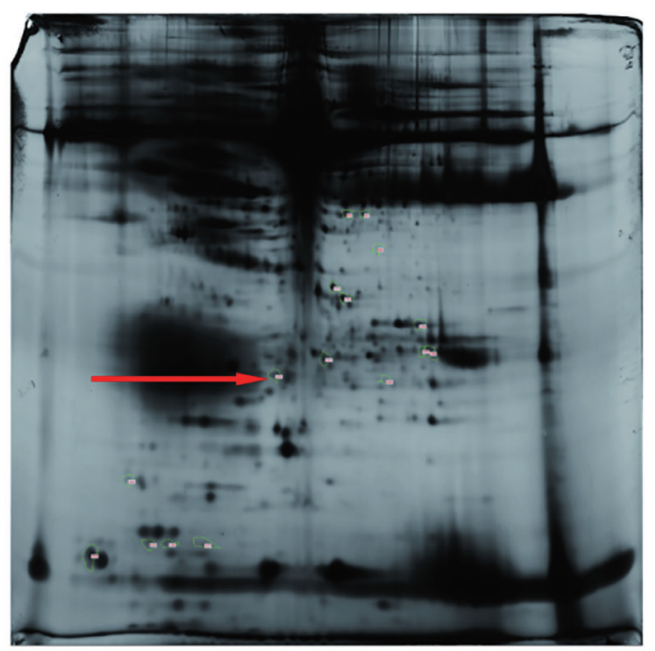

Control vs. Blank

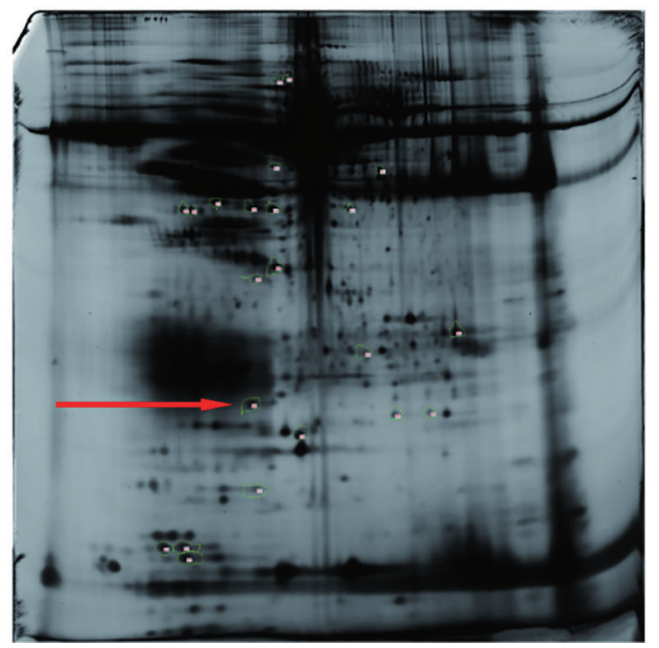

Blank vs. Test

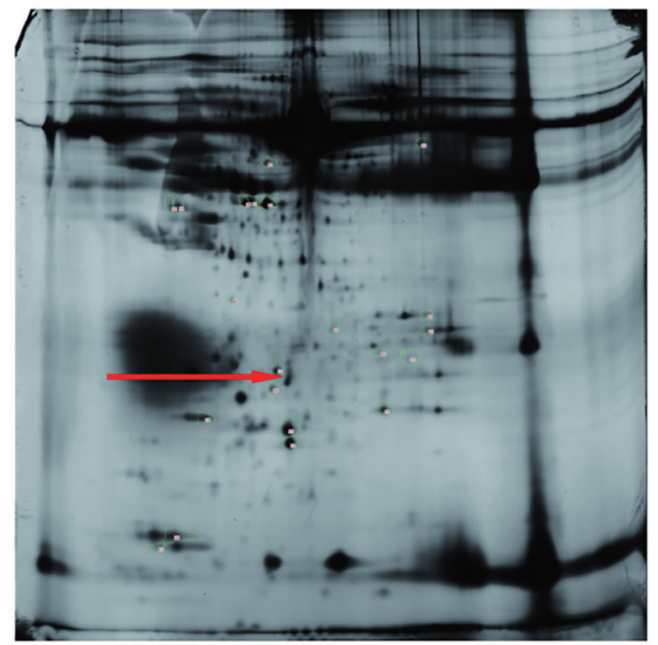

Test vs. Control

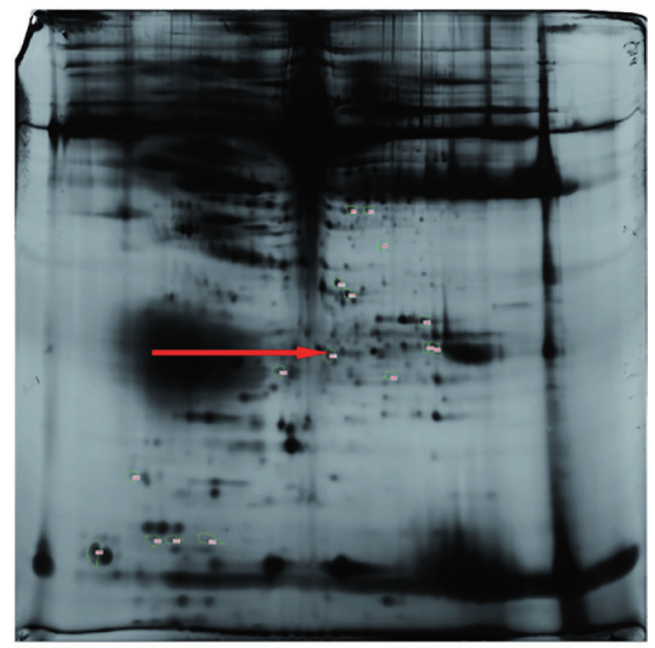

Control vs. Test

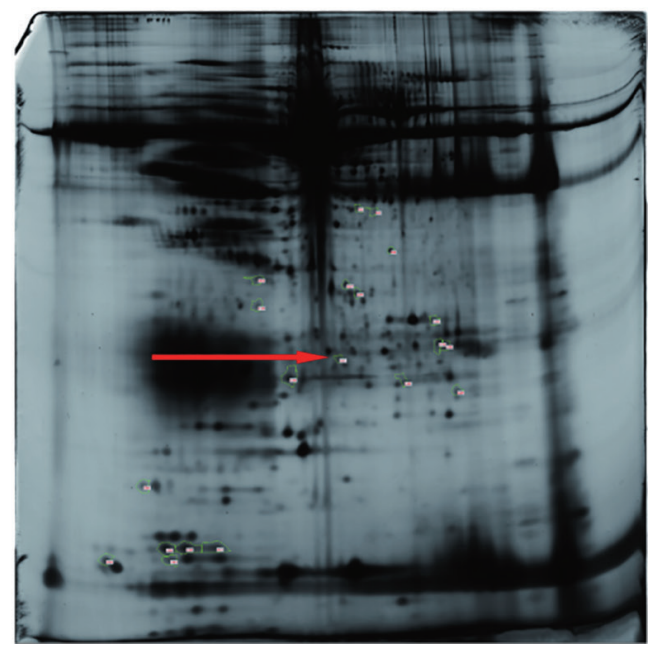

Figure 2 Comparison of electrophoresis diagrams of joint fluid in each group. 
A

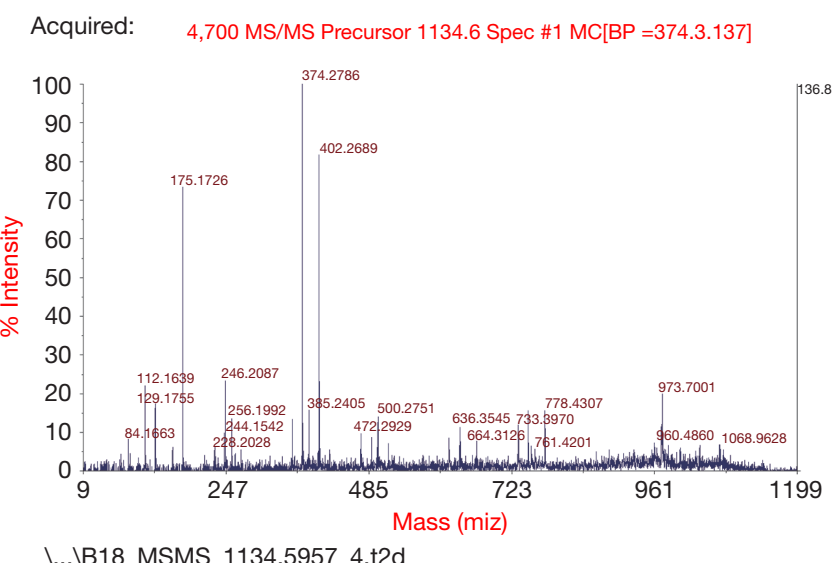

B

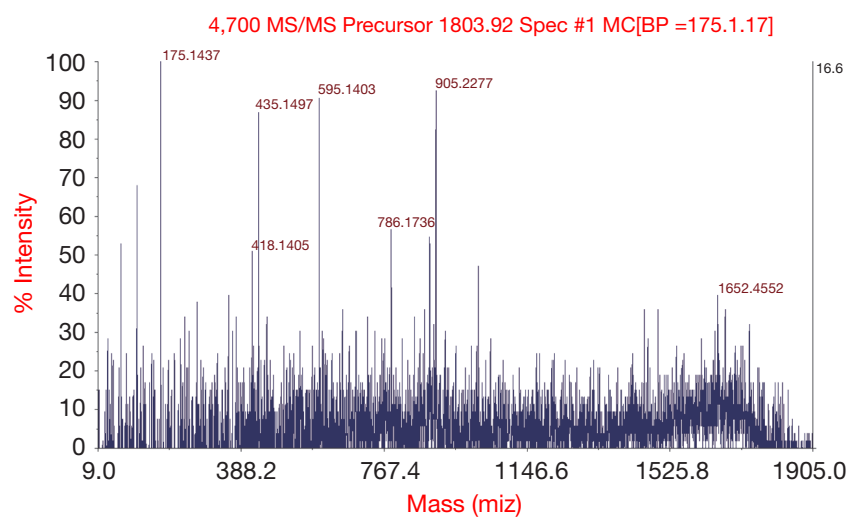

।...IF8_MSMS_1803.9237_7.t2d

C

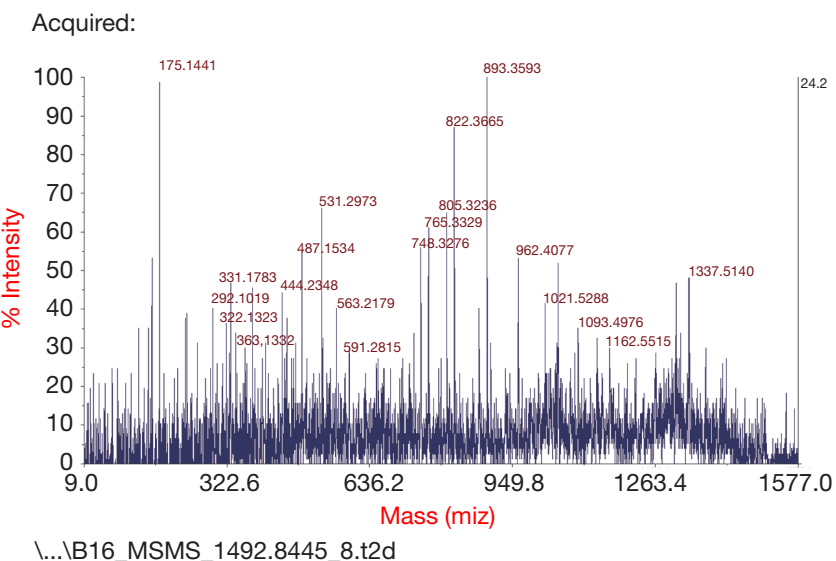

Figure 3 Mass spectrometry identification data of three proteins. (A) Protein spectrum identification result with a molecular weight of 23,429.4. (B) Protein spectrum identification result with a molecular weight of 57,431.4. (C) Protein spectrum identification result with a molecular weight of 26,071.1. metabolism. In this experiment, we confirmed that there are three meaningful proteins in the synovial fluid of the knee joint after transplantation of allogenic decalcified bone. The first was an unnamed protein with a molecular weight of $23,429.4$. According to its population, it has important mitotic promoting molecules and is an inducing factor of morphogenesis and differentiation, which participates in the process of growth and development and the repair of tissue injury; we thus speculated that it has a role in the regeneration of articular cartilage. The second was a protein with a molecular weight of $57,431.4$, named catalase. In tumor research, the upregulation of catalase has been found to effectively alleviate tumor hypoxia and improve the therapeutic effect of $\mathrm{O}_{2}$-dependent photodynamic therapy $(20,21)$. The decreased expression of catalase has also been associated with the hypertrophy of the lumbar spinal canal stenosis of the yellow ligament (22). In stem cell research, highly expressed catalase could significantly enhance the ability of bone marrow mesenchymal stem cells to resist oxidative stress injury $(23,24)$. Furthermore, in the process of repairing cartilage defects with boron and hyaluronic acid, the expression of catalase was found to be higher in blood and articular cartilage (25). The third protein had a molecular weight of 26,071.1 and is named EC-SOD. EC-SOD is the main SOD isozyme in blood vessel walls, normal cartilage, and synovium fluid, and may have an important role in the antioxidant capacity of these tissues (26). It was reported that (27) EC-SOD activity in synovium fluid of patients with rheumatoid arthritis (RA) was obviously lower than that of patients with noninflammatory arthropathy. Yu and colleagues (28) found that the overexpression of EC-SOD in joint synovial cells can protect the joints from destruction by inhibiting the production of pro-inflammatory factors and matrix metalloproteinases (MMPs). Therefore, we speculated that these identified proteins may be involved in the repair of joint defects, but further structural analysis and functional mechanism research are needed.

\section{Conclusions}

Our study found three candidate proteins in joint synovial fluid that may be involved in joint regeneration and repair within the process of articular cartilage regeneration. The results of this experiment provide a preliminary basis for the next stage of experiments and offer new ideas for the indepth discussion concerning the regeneration mechanism of articular cartilage. 


\section{Acknowledgments}

Funding: None.

\section{Footnote}

Reporting Checklist: The authors have completed the ARRIVE reporting checklist. Available at http://dx.doi. org/10.21037/atm-20-8195

Data Sharing Statement: Available at http://dx.doi. org/10.21037/atm-20-8195

Conflicts of Interest: All authors have completed the ICMJE uniform disclosure form (available at http://dx.doi. org/10.21037/atm-20-8195). The authors have no conflicts of interest to declare.

Ethical Statement: The authors are accountable for all aspects of the work in ensuring that questions related to the accuracy or integrity of any part of the work are appropriately investigated and resolved. Experiments were performed in compliance with Chinese national guidelines for the care and use of animals. This study was approved by the Medical Ethics Committee of Guangzhou Red Cross Hospital, Jinan University (no. 2018-077-01).

Open Access Statement: This is an Open Access article distributed in accordance with the Creative Commons Attribution-NonCommercial-NoDerivs 4.0 International License (CC BY-NC-ND 4.0), which permits the noncommercial replication and distribution of the article with the strict proviso that no changes or edits are made and the original work is properly cited (including links to both the formal publication through the relevant DOI and the license). See: https://creativecommons.org/licenses/by-nc-nd/4.0/.

\section{References}

1. Lijun $W$, Xinming $G$. The articular cartilage injury prevention and control. People's Military Medical Press; 2004.

2. Baker B, Becker RO, Spadaro J. A study of electrochemical enhancement of articular cartilage repair. Clin Orthop Relat Res 1974:251-67.

3. Corvol MT, Tahiri K, Montembault A, et al. Cell therapy in cartilage repair: cellular and molecular bases. J Soc Biol 2008;202:313-21.
4. Zhang Y, Lei Z, Qi Y, et al. Adipose-derived stem cell sheet encapsulated construct of micro-porous decellularized cartilage debris and hydrogel for cartilage defect repair. Med Hypotheses 2017;109:111-3.

5. Minas T, Nehrer S. Current concepts in the treatment of articular cartilage defects. Orthopedics 1997;20:525-38.

6. Chiang H,Jiang CC. Repair of articular cartilage defects: review and perspectives. J Formos Med Assoc 2009;108:87-101

7. O'Driscoll SW. Articular cartilage regeneration using periosteum. Clin Orthop Relat Res 1999:S186-203.

8. Iwamoto M, Ohta Y,Larmour C, et al. Toward regeneration of articular cartilage. Birth Defects Res C Embryo Today 2013;99:192-202

9. Siming L, Shengquan Z, Xiaohong Y. Studies on the Bone and Cartilage Inductive Capacity of Demineralized Osteoarticular Allograft Transplantation. Chinese Journal of Orthopaedics 1998;18:367-70.

10. Feng WW, Yang GZ, Yin WH, et al. Intra-articular chondrogenic activity of bone marrow mesenchymal stem cells co-cultured with allogenic demineralized bone matrix. Chinese Journal of Tissue Engineering Research 2013;16:8741-6.

11. Li SM, Yang XH, Zhang SQ. Mass decalcified allograft of bone and joint: establishment of an animal model of segmental articular defect. Guangzhou Medical Journal 1998;29:15-7.

12. Iwata H, Sakano S, Itoh T, et al. Demineralized bone matrix and native bone morphogenetic protein in orthopaedic surgery. Clin Orthop Relat Res 2002:99-109.

13. Gruskin E, Doll BA,Futrell FW, et al. Demineralized bone matrix in bone repair: history and use. Adv Drug Deliv Rev 2012;64:1063-77

14. Cho H, Bucciarelli A,Kim W, et al. Natural Sources and Applications of Demineralized Bone Matrix in the Field of Bone and Cartilage Tissue Engineering. Adv Exp Med Biol 2020;1249:3-14.

15. Yanaga H, Yanaga K,Imai K, et al. Clinical application of cultured autologous human auricular chondrocytes with autologous serum for craniofacial or nasal augmentation and repair. Plast Reconstr Surg 2006;117:2019-30; discussion 2031-2

16. Kim JB, Lee DY,Seo SG, et al. Demineralized Bone Matrix Injection in Consolidation Phase Enhances Bone Regeneration in Distraction Osteogenesis via Endochondral Bone Formation. Clin Orthop Surg 2015;7:383-91 
17. Ma TW, Li Y, Wang GY, et al. Changes in Synovial Fluid Biomarkers after Experimental Equine Osteoarthritis. J Vet Res 2017;61:503-8.

18. Zhang C, Wei X, Chen C, et al. Indian hedgehog in synovial fluid is a novel marker for early cartilage lesions in human knee joint. Int J Mol Sci 2014;15:7250-65.

19. Chockalingam PS, Glasson SS, Lohmander LS.

Tenascin-C levels in synovial fluid are elevated after injury to the human and canine joint and correlate with markers of inflammation and matrix degradation. Osteoarthritis Cartilage 2013;21:339-45.

20. Chang M, Hou Z, Wang M, et al. Cu2 MoS4 / Au Heterostructures with Enhanced Catalase-Like Activity and Photoconversion Efficiency for Primary/ Metastatic Tumors Eradication by Phototherapy-Induced Immunotherapy. Small 2020;16:e1907146.

21. Hei Y, Teng B, Zeng Z, et al. Multifunctional Immunoliposomes Combining Catalase and PD-L1 Antibodies Overcome Tumor Hypoxia and Enhance Immunotherapeutic Effects Against Melanoma. Int J Nanomedicine 2020;15:1677-91.

22. Chen T, Chen HS, Yi JF. Study on the expression of catalase in ligamentum flavum hypertrophy. Anhui Medical and Pharmaceutical Journal 2020;24:681-4.

23. Yuan D, Peng W, Fei Z, et al. Pretreatment with lowconcentration hydrogen peroxide enhances anti-oxidative

Cite this article as: Wang M, Dai T, Feng Z, Meng Q, Wang W, Li S. Study on specific proteins involved in articular cartilage regeneration activity induced by decalcified bone transplantation. Ann Transl Med 2021;9(2):160. doi: 10.21037/ atm-20-8195 stress ability of bone marrow mesenchymal stem cells. Chinese Journal of Tissue Engineering Research 2019;23:1982-8.

24. Liu JH, Hao P, Xuan L. Inhibitory effects of thymosin $\beta 4$ on H_2O_2-induced oxidative damage and subsequent cell apoptosis of rabbit corneal keratocytes. Rec AdvOphthalmol 2019;39:207-12.

25. Korkmaz M, Turkmen R, Demirel HH, et al. Effect of Boron on the Repair of Osteochondral Defect and Oxidative Stress in Rats: an Experimental Study. Biol Trace Elem Res 2019;187:425-33.

26. Adachi T, Toishi T, Takashima E, et al. Infliximab neutralizes the suppressive effect of TNF-alpha on expression of extracellular-superoxide dismutase in vitro. Biol Pharm Bull 2006;29:2095-8.

27. Marklund SL, Bjelle A, Elmqvist LG. Superoxide dismutase isoenzymes of the synovial fluid in rheumatoid arthritis and in reactive arthritides. Ann Rheum Dis 1986;45:847-51.

28. Yu DH, Yi JK, Yuh HS, et al. Over-expression of extracellular superoxide dismutase in mouse synovial tissue attenuates the inflammatory arthritis. Exp Mol Med 2012;44:529-35.

(English Language Editor: J. Gray) 